\title{
The Role and Challenges of Ward Development Committees in Promoting Grassroots Health Awareness in Ogun State Nigeria
}

\author{
Azuh Dominic Ezinwa \\ Department of Economics and Development Studies, College of Business \& Social Sciences, Covenant \\ University, Ota, Ogun State, Nigeria
}

\begin{abstract}
The study was carried out in Ado-Odo/Ota Local Government Area to examine the potential influence of ward development committees (WDCs) in providing health service support to health services in rural and semi-rural areas. Data were generated through survey approach using questionnaire instrument. The study employed multi-stage random sampling technique in the selection of the sample. Ado-Odo/Ota Local Government Area was purposively selected in the first stage. In the second stage, 12 political wards were randomly selected out of 16 in the local government area. Out of the 12 randomly selected political wards, 192 respondents were interviewed; out of which 185 of respondents responded positively. A focus group discussion was conducted to complement quantitative data. Information on the activities and challenges facing WDCs in the study area were collected in addition to demographic data of the respondents. Data were analyzed using descriptive statistics. The study found that WDCs engaged in several activities such as promoting of immunisation programmes, environmental waste and sanitation education, health promotion and collaboration activities. Constraints hindering the work of the committees were identified and recommendations were proffered to government to provide financial support to WDC intervention programmes to facilitate the work of WDCs in the study area.
\end{abstract}

Keywords: Challenges, healthcare services, primary health care, rural health facility, ward development committees.

\section{Introduction}

People centered activity is the heart of primary health care (PHC) and a sure way to programme sustainability. In other words, peoples' health care should be the concern of the people themselves and not only of the health personnel. There are several hindrances towards utilisation of health care services and developmental interventions particularly in rural areas. Public health efforts through community associations, leaders and community collaborations are required nowadays to maximize the benefits of modern health care services such as disease prevention, health promotion and protection. The goal of the National Health Policy in Nigeria is same as bringing comprehensive health care to all the citizens of Nigeria leading to sound health and productivity [1]. A good national health system should serve the interest of those at grassroots for which health care services elude and their contributions remain crucial for economic development. The ward development committee (WDC) was designed and developed as a social strategy for encouraging community participation and access to primary health care services [2]. WDCs help to ensure complete ownership by members of the community of all primary health issues such as health promotion and community mobilisation, maternal and newborn child health services, nutrition, control of communicable and non-communicable diseases and sexual and reproductive health. Furthermore, it also includes issues of water, sanitation and hygiene (WASH) including waste disposal.

The Alma-Ata conference in 1978 included in its components among others, education concerning preventing health problems, adequate supply of safe water and basic sanitation; immunisation against the major infectious diseases; prevention and control of locally endemic diseases and appropriate treatment of common diseases [3]. Recent study found that there has been steady rise in disease outbreaks and PHCs are getting low patronage particularly among rural communities [4]. More worrisome is the fact that a reasonable proportion of pregnant mothers still seek care from non-medical personnel [5]. Incidentally, primary health care, which is core instrument in achieving good health for all is not doing enough towards realizing the objectives of the national health policy. Ironically, most of the rural PHC facilities serve poor, ignorant and people already adapted to their cultural practices who may ignore the low quality services that PHCs provide by staying at home, and consult non-trained health personnel except only in emergency, often too late for life-saving interventions.

According to researchers primary health care, which is supposed to be the bedrock of the country's health care policy, is currently catering for less than $20 \%$ of the potential patients [6]. Similarly, in a study conducted by Nigeria's Federal Ministry of Health and United Nations Population Funds on the quality of care, found $18.5 \%$ of the 4500 facilities surveyed had the capacity to provide emergency obstetric care [7]. In a 
baseline assessment study of facilities in three states of Nigeria (Katsina,Yobe, and Zamfara) to assess the potential capacity of hospitals in those states to provide the continuum of care for maternal, newborn, and child health including skilled birth attendance and essential obstetric care, found that these states had a serious health worker shortage, and fewer people living within ten kilometres of a health centre [8].

It has been observed that some rural dwellers in Nigeria tend to underuse the services due to perceptions of poor quality and inadequacy of available services [9]. A recent study on health services in rural Nigeria found increase in health care utilisation by women with respect to antenatal care visits, postnatal visits, and use of contraceptive methods when compared to data from the 2013 NDHS [10]. Ekwureke affirms that rural/remote dwellers have higher morbidity and mortality rates than urban dwellers, and restricted access to health Services [11]. A recent study reveals that despite an in-built symbiotic relationship between the PHC and rural communities in Nigeria, the goal of development through the PHC is constrained by poor human resource for PHC both in qualitative and quantitative terms, administrative lapses by government, and ignorance on the part of the rural citizens [12].

Healthy survival is still a challenge despite massive health infrastructure, life-saving drugs, and dramatic advances in medical research and technology, particularly in developing countries [13] and the PHC has come onboard to ameliorate the ugly situation. PHC still suffers from unawareness problems as greater proportion of the rural population in many communities do not seem to know what PHC is all about nor are they aware of the various services under the PHC scheme [14]. Many rural masses lack the knowledge and causes of acute respiratory infection, consequences of unsafe drinking water, poor refuse disposal habits and unhygienic behaviors. The knowledge of the above has become imperative as the 2013 Nigeria's Multiple Indicator Cluster Survey reports that only 59\% of households in Nigeria use improved water source and $31 \%$ of households use an improved sanitation facility. The report added that only $38 \%$ of children received all their vaccines by the age of 12 months [15] (MICS 2013). Some scholars observed that PHC is not only community based but it requires the participation of community members, nurses, health workers so that they interrelate and interconnect to eradicate health problems [16], [17].

Ward Development Committee is an initiative of National Primary Health Care Development Agency (NPHCDA), designed to strengthen local communities to advocate for them in terms of knowledge dissemination of health information with cognizance of socio-cultural context in which health actions are being taken. It provides information to villagers that assist them to take control over their own lives, change their risky health practices, contributes to activities for community health improvement programmes, reduces conflict of interests, enhances credibility and cooperation among members, and ensures greater acceptance of new novel ideas and aids utilization and sustainability of health care services at grassroots. Volunteers share time, resources among others to execute crucial projects or meet their respective objectives/targets. Incidentally, majority of people do not know about the existence of WDCs and talk less of knowing their activities towards developmental issues.

The committees are made up of volunteer community members who can help to identify health and development problems within the community and promote demand for quality services by getting people to act and change their attitudes and behaviour. WDC aids in identifying health and social needs of the communities in the ward and plan for meeting those needs. In addition, WDCs collaborates with government organizations and private agencies such as NGOs for various intervention programmes. Invariably, the WDCs also serve as a pressure group for LGA support in providing health and other developmental services for the people in the ward. WDC is a confidence booster and tackles various reasons that are adduced for the underuse of available services. Health behaviours are influenced by culture and thus respect for the community's culture becomes essential to maximize health care services and crucial for healthcare programme sustainability.

There had been several studies conducted on issues relating to primary health care delivery services but none had endeavoured to examine the role /activities and challenges of WDCs in assisting to support PHCs to achieve the goals for which it was established. As the Federal Ministry of Health (FMOH) noted that access in its various dimensions such as distance to PHC facility, cost, cultural factors and access to information are all embedded in health care provision [18]. Hence, the need for the current study, of which the objectives were:

i. To examine the activities of WDC with respect to health care services,

ii. Highlights the existence of constraints mitigating these activities, and

iii. Proffer suggestions on how to reduce these challenges and boost contributions of WDCs towards supporting modern health practices through PHCs in the study area.

The location for this study is Ado-Odo/Ota Local Government Area (LGA) of Ogun state, Nigeria. The local government was created in 1989. Ota is the headquarters of the local government and is among the popular towns in the state. Ado-Odo Ota is the second largest local government area in Ogun State with several industries and covers about 1,460 square kilometres. The local government share boundaries with Yewa South and Ifo Local Governments in the West, Obafemi Owode Local Government in the North East and in the South 
it borders Lagos state, the commercial capital of Nigeria respectively. The local government is agrarian in nature but has been overshadowed by trans-boarder trading and commerce as a result of its proximity to Lagos and Cotonou, a town in the Republic of Benin. Despite the above, the local government area is bedeviled with lacks in terms of basic infrastructural facilities (e.g. lack of portable water, electricity and road networks, etc), and increasing rate of slums and squalor. Health facility is far from the masses and most of them need grave attention with respect to infrastructure, drugs, deliverables and personnel.

\section{Method}

The study was a baseline survey across Ado-Odo/Ota Local Government Area to examine the potential influence of ward development committees (WDCs) in providing health service support to health services in rural and semi-rural areas in Ota. Data were generated through survey approach using questionnaire instrument. The study employed multi-stage random sampling technique in the selection of the sample. Ado-Odo/Ota Local Government Area was purposively selected in the first stage. In the second stage, all the political wards in the local government area were included in sampling frame and 12 were randomly selected. Out of the 12 randomly selected political wards, 192 respondents were surveyed; out of which 185 of them responded positively as 7 respondents did not give their consent. Respondents are WDC members in that particular ward. Thus, 185 respondents constituted the sample size. In addition, qualitative information was generated through focus group discussions (FGDs) to complement quantitative data that were gathered. Information on the activities and challenges facing WDCs in the study area were collected in addition to demographic data of the respondents. Data were analyzed using descriptive statistics such as percentages and graphics. Qualitative information was thematically analyzed in order to achieve the research objectives. The data collection instrument was pretested for reliability and validity, and necessary modifications and revisions were carried out after the pilot study to perfect the instrument. The FGD participants were drawn from all the wards to harvest their experiences in the study location. Ten (10) persons constituted the group and all the rules of FGDs were applied.

\section{Results}

Table 1: Distribution of Respondents according to Socio-demographic Characteristics

\begin{tabular}{|c|c|c|c|c|c|}
\hline Variable & No & Percent & Variable & No & Percent \\
\hline Sex & & & Age & & \\
\hline Male & 118 & 63.8 & Below 30 & 3 & 1.6 \\
\hline Female & 67 & 36.2 & $30-40$ & 44 & 23.8 \\
\hline \multirow[t]{3}{*}{ Total } & 185 & 100.0 & $41-50$ & 60 & 32.4 \\
\hline & & & 51 and Above & 78 & 42.2 \\
\hline & & & Total & 185 & 100.0 \\
\hline Religion & & & Education & & \\
\hline Christianity & 88 & 47.6 & None & 12 & 6.5 \\
\hline Islam & 86 & 46.5 & Primary & 26 & 14.0 \\
\hline Traditional & 11 & 5.9 & Secondary & 84 & 45.4 \\
\hline \multirow[t]{2}{*}{ Total } & 185 & 100.0 & Post-Secondary & 63 & 34.1 \\
\hline & & & Total & 185 & 100.0 \\
\hline \multicolumn{6}{|l|}{ Occupation } \\
\hline Not Working & 17 & 9.2 & & & \\
\hline Self Employed & 73 & 39.5 & & & \\
\hline Civil/Public Servant & 15 & 8.1 & & & \\
\hline Private Sector employee & 12 & 6.5 & & & \\
\hline Farming & 17 & 9.2 & & & \\
\hline Trading & 40 & 21.6 & & & \\
\hline Artisan & 11 & 5.9 & & & \\
\hline Total & 185 & 100.0 & & & \\
\hline
\end{tabular}

Source: Author's computation 2017

The sex composition of the respondents showed that males constitute almost two thirds of the respondents (63.8\%) and the proportion of female counter parts was slightly higher than one third (36.2\%). Age of respondents showed that subjects with age 51 and above accounted for 42.2 percent and followed closely by those respondents whose age bracket were $41-50$ (32.4\%). However, respondents with 30-40 age brackets registered 23.8 percent and those with age below 30 years accounts for the least $(1.6 \%)$. The religious affiliation indicated that $47.6 \%$ of total respondents interviewed were Christians, followed closely by Islam religion $(46.5 \%)$ and least proportion of the respondents $(5.9 \%)$ belong to the traditional religion as depicted in Table 1 and Fig 1. 


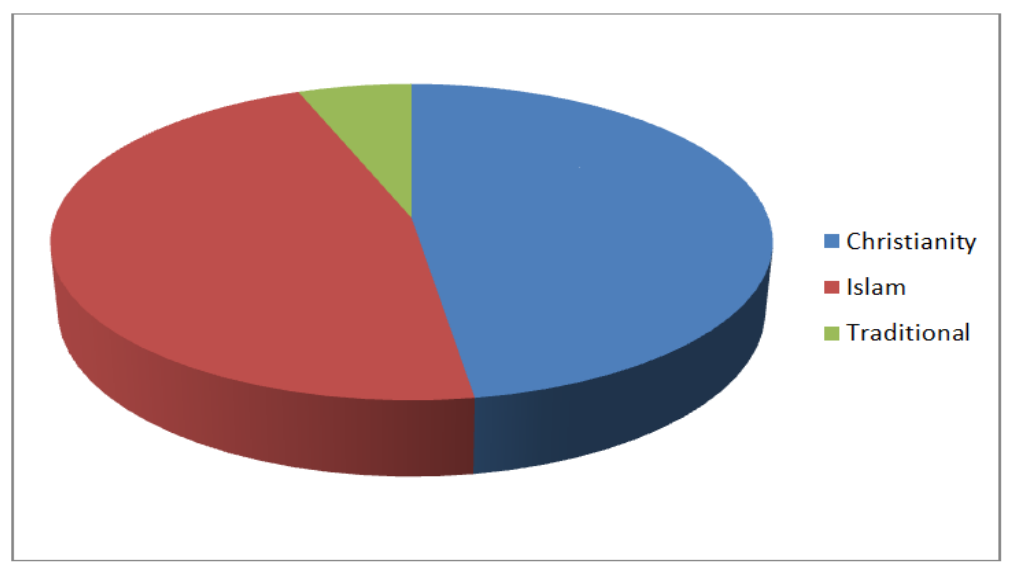

Fig 1: Distribution of respondents according to Religion

In the social sphere, respondents with secondary education accounted for the highest proportion (45.4\%). Those with post-secondary education followed with 34.1percent. Nevertheless, respondents with primary education and those with no education registered reduced proportions (14.0\%) and (6.5\%) respectively as represented in Table 1 and Fig 2.

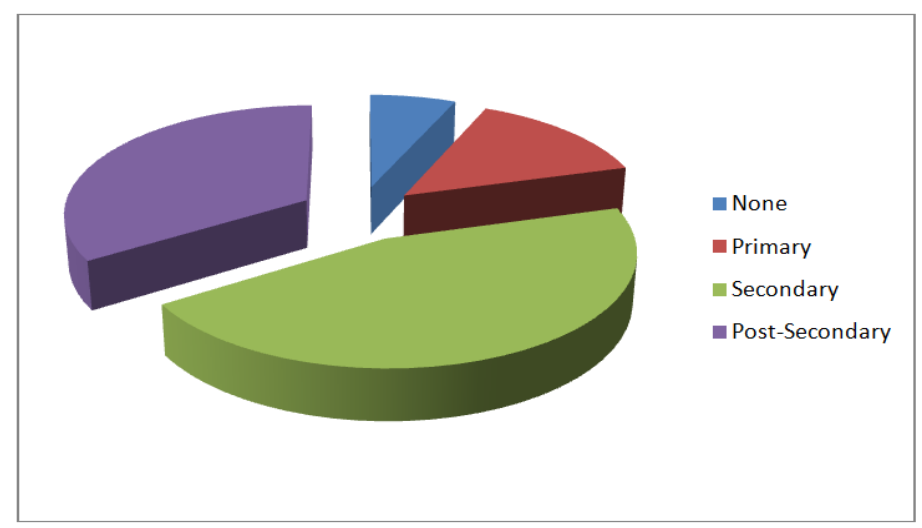

Fig 2: Distribution of respondents according to Education

The occupation of respondents showed that self employed registered the highest proportion of respondents (39.5\%), followed by traders $(21.6 \%)$, farming and respondents that are not working registered similar proportion $(9.2 \%)$ respectively (see Table 1$)$. However, this is followed by civil/public servants $(8.1 \%)$, private sector employees (6.5\%) and artisans (5.9\%) respectively as shown in Fig 3.

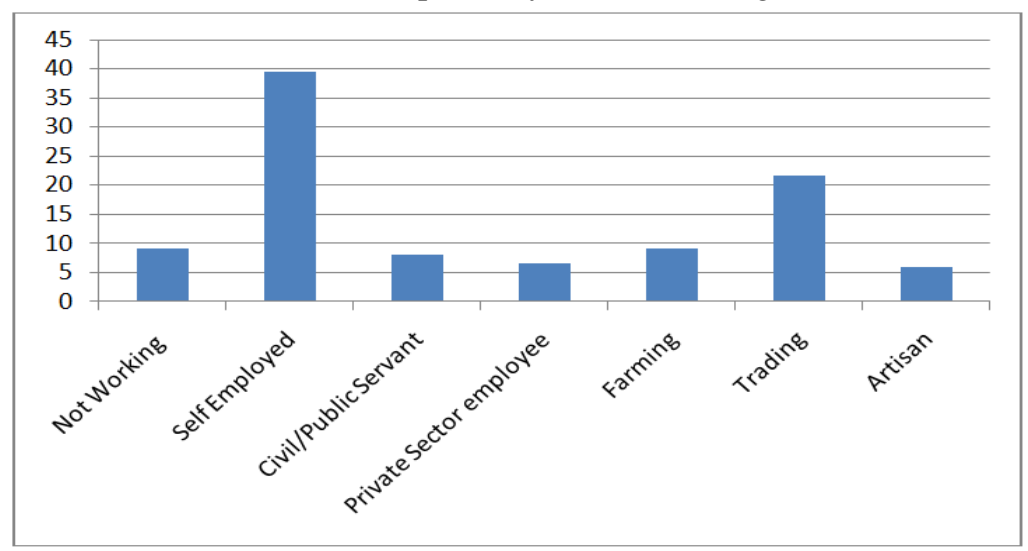

Fig 3: Distribution of respondents according to Occupation

Table 2: Distribution of Respondents according to Ward Development Committees Activities/Programmes

\begin{tabular}{|l|l|l|l|}
\hline Nature of Activity & Yes (\%) & No (\%) & Total (\%) \\
\hline Collaboration with govt agencies/NGOs & $62.2(115)$ & $37.8(70)$ & 100.0 \\
\hline Engagement in health education and promotion programmes & $69.7(129)$ & $30.3(56)$ & 100.0 \\
\hline Engagement in environmental waste and sanitation education & $62.7(116)$ & $37.3(69)$ & 100.0 \\
\hline Engagement in promoting Immunisation programs & $78.9(146)$ & $21.1(39)$ & 100.0 \\
\hline
\end{tabular}


On examination of respondents according to WDCs activities/programmes, it was observed that across all the four categories of activity considered those that affirmed positively had greater proportion than respondents on the contrary as indicated by 'yes \%' and 'no \%' in Table 2 . Among the respondents that responded positively to the activities of WDCs, those that stated engagement in promoting immunisation programmes was at front burner $(78.9 \%)$, followed by engagement in health education and promotion programmes (69.7\%). However, those respondents who engaged in environmental waste disposal and sanitation education, and collaboration with government agencies and NGOs equally registered almost similar substantial proportion $(62.7 \%)$ and $(62.2 \%)$ respectively (see Fig 4$)$.

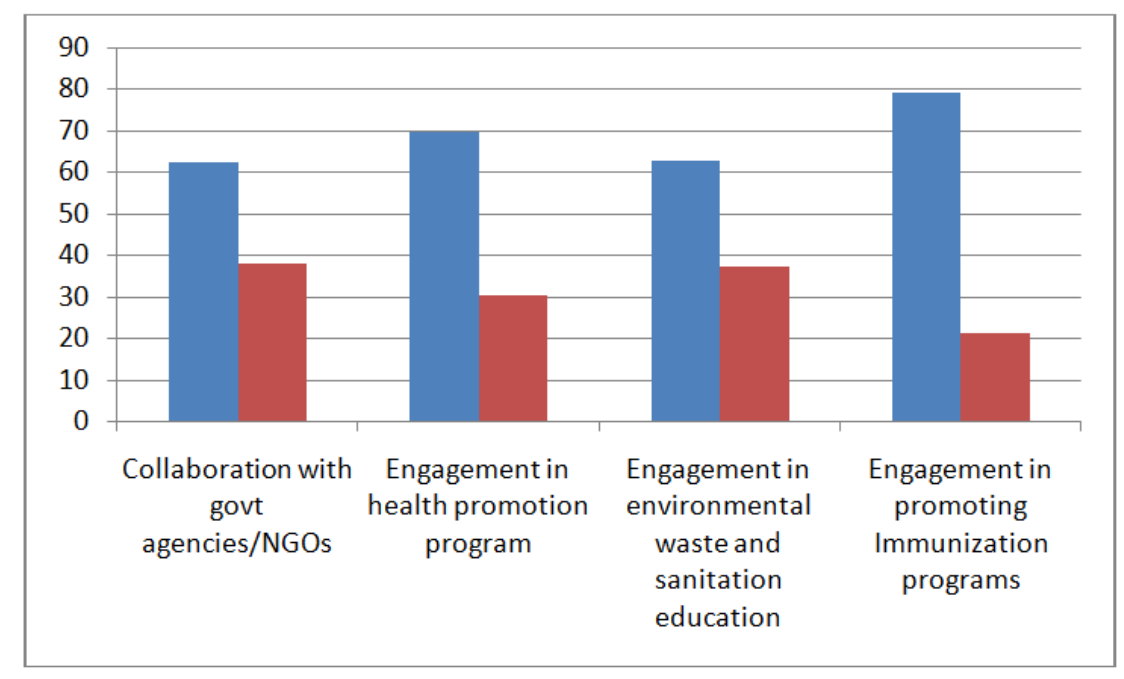

Fig 4: Distribution of respondents according to ward development committees' activities

Table 3: Respondents according to major challenges facing Ward Development Committees

\begin{tabular}{|l|l|l|}
\hline Nature of Challenge & No & Percent \\
\hline Lack of motivation of members & 20 & 10.8 \\
\hline Vehicle and bad road & 37 & 20.0 \\
\hline Office apartment/Secretariat & 30 & 16.2 \\
\hline Lack of equipment(-PAS, furniture, instructional materials, fan etc. & 25 & 13.5 \\
\hline Financial constraint & 73 & 39.5 \\
\hline Total & 185 & 100.0 \\
\hline
\end{tabular}

\section{Source: Author's computation}

With respect to WDCs constraints, respondents were also asked to indicate major challenges facing the smooth operation of their activities (see Table 3). On examination of these challenges, financial constraint accounts for the highest proportion (39.5\%), followed by vehicle and bad road (20\%), and office apartment or secretariat (16.2\%). Nevertheless, other challenges such as lack of equipment such as public address system(PAS), furniture, instructional materials, fans, etc and lack of members' motivation registered $13.5 \%$ and $10.8 \%$ respectively (see Fig 5).

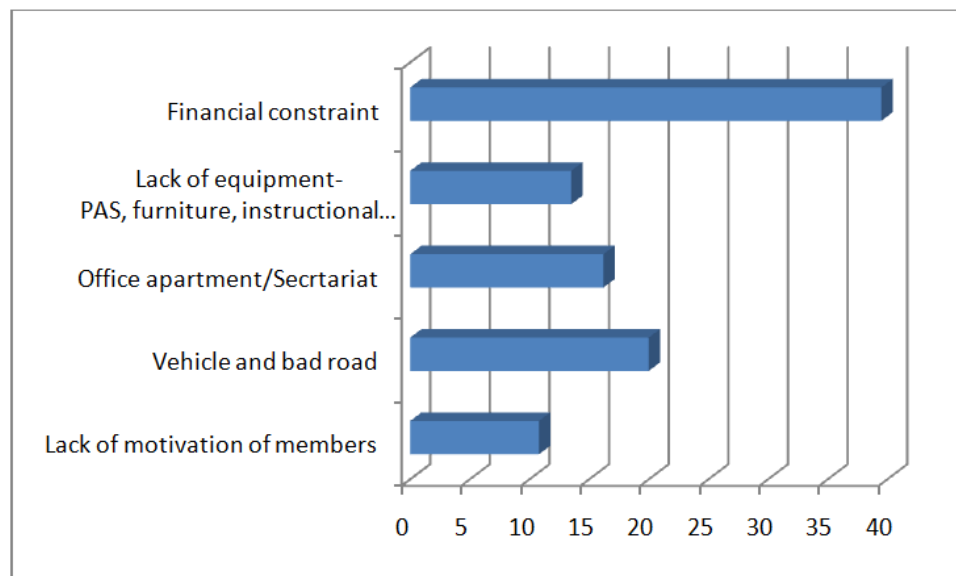

Fig 5: Distribution of respondents according to challenges facing ward development committees 


\section{Presentation of Findings on Qualitative Study \\ Low awareness of WDCs by the masses}

Majority of the participants agreed that the awareness of WDCs by the masses was low and some were quick to state that this perhaps might be due to low level of sensitisation campaign among the various communities as one of the participants stated.

"People do not know us as our activities are hindered by money but I agree we have to do more work for them to know us (sic) [Focus Group Discussion Participant \{FGDP\}, 41 year old from Ota]".

Another participant revealed:

"Our members are not regular to our meetings and intervention programmes because their works don't give them chance and they cannot leave their jobs since we don't get salary here (sic) [Focus Group Discussion Participant $\{F G D P\}, 45$ year old from Ota]".

\section{About WDCs activities}

Participants observed great enthusiasm from the masses during some of their activities such as immunisation mobilisation and health promotion programmes. This may be due to the fact that women and children have high morbidity and mortality rates which draw them towards these activities. The drawn out theme was that any programme that involves distribution of items witness greater participation. One of the participants said.

"People come more when they know we will give them some items like insecticide treated nets(ITN)/bed nets and free check up, medicines and immunisation but we don't organize this always because we don't have ITNs and medicines every time (sic) [Focus Group Discussion Participant $\{F G D P\}$, 50 year old from Ota]".

When asked if the committee provided borehole(s) and waste bins to people in their wards another participant revealed.

"We want to give them but there is no money to provide such things unless when we get money from the government or any partner and we don't know when (sic) [Focus Group Discussion Participant $\{F G D P\}, 43$ year old from Ota]".

\section{On the constraints facing WDCs activities}

The challenges hindering the operations of WDCs activities in the various wards, attracted similar chorus answers. The theme derived is that WDCs faced with financial constraint and lack basic items that will enhance their assignment. FGDs also supported this claim as a participant divulged thus:

"We don't have money and we cannot go far even to fuel our machines (motorcycles). Money is a big problem to our intervention activities. We want government to assist us with money to acquire our needs such as jungle boots as our roads are bad, umbrella/raincoats, even van for our campaigns, loud speakers, mega phones, posters and instructional materials and even office space we know get (sic) [Focus Group Discussion Participant $\{F G D P\}, 46$ year old from Ota]".

Another participant collaborates on the above assertion and stated:

"Most times we don't complete our programmes or campaigns because the hired vehicle refuse to turn up after 1 or 2 days and will not refund back our money. Hope your study will help to get us money from them (government) so that we can be happy and people can see our work (sic) [Focus Group Discussion Participant $\{F G D P\}, 38$ year old from Ota]".

Another theme disclosed during the FGDs was that monetary incentive will engender the dedication of WDC members. This FGDs accented to this assertion as seen in a candid expression of another young participant retorted:

"We need money to be motivated and without money we cannot be fully dedicated because we have families and need food to make them happy as we are not getting salary. Government should give us something to compensate us for our involvement in WDCs (sic) [Focus Group Discussion Participant $\{F G D P\}, 35$ year old from Ota]".

\section{Discussions}

The apathy towards PHC patronage particularly in rural areas is very high and there is need to explore ways of drawing rural masses back to the health facility, as this was the core reason for which PHC was established. To restore confidence and patronage among the people, it is imperative for WDCs to intensify their work by mobilizing and sensitizing rural masses on the need to adopt a healthy life style and patronise health care facilities within their areas. In order for WDCs to perform their roles efficiently towards better public health care support for rural masses, it is necessary to conduct this kind of baseline survey study on the activities and challenges hindering the operations of WDCs in Ado-Odo/Ota local government area for better public health policy. 
The study revealed that males had the highest proportion of respondents $(63.8 \%)$ compared to women. This might be due to the fact that women require permission from their husbands to join in such committees and moreover females also take care of the homes. Religion showed that both Christians and Islam had almost same proportions of $47.6 \%$ and $46.5 \%$ respectively. The age of respondents revealed that young age category (below 40 years) was less $(25.40 \%)$ when compared to the aged 51 and above $(42.2 \%)$. This perhaps might be due to the fact that young people would be more interested in paid jobs that will guarantee food and comfortable living for their families rather than volunteer work without pay. The occupational status of the respondents showed that self-employed and trading registered highest proportion, 39.5\% and $21.6 \%$ respectively. The high proportion noticed in self employed category might be as a result of people who have retired from service and went into small income generating outfits and in addition to those who have no job and resorted to doing one thing or the other for sustenance. The other remarkable observation with respect to secondary and post secondary education that accounted for almost four-fifths of the respondents and secondary education accounted for $45 \%$.

With respect to the activities and constraints facing WDCs in the study area, it was observed that across all the four categories of activity considered those that affirmed positively had greater proportion than respondents on the contrary as indicated by 'yes \%' and 'no \%' in Table 2 and Fig 4. Among the respondents that responded positively to the activities of WDCs, those that stated engagement in promoting immunisation programs was at front burner $(78.9 \%)$, followed by those who engaged in health education and promotion programmes $(69.7 \%)$. This is because people tend to imbibe more of public health and promotion of children compare to adult which is in consonance with earlier study [2].

However, those respondents who engaged in environmental waste disposal and sanitation education, and collaboration with government agencies and NGOs equally registered almost substantial similar proportion $(62.7 \%)$ and (62.2\%) respectively (see Table 2 and Fig 4). As a result of adverse implications of poor environmental sanitation on health of the masses, the campaign on proper waste disposal is being intensified in some Local Government Areas and States although WDCs operations in this direction are being retarded due to constraints in finance, vehicle and equipment as mentioned by participants during FGDs. The major challenge of WDCs factors inhibiting the WDC involvement in rural health support was lack of finance to effect their activities as earlier highlighted. This factor alone accounted for 39.5\% of all responses, see Table 3 . Next to this was vehicle and bad road (20\%), and office apartment or secretariat (16.2\%) which was mentioned by FGDs participants as factors hindering their operations. The study showed that inadequate equipment such as public address system (PAS), furniture, instructional materials/posters, fan among others accounted for $13.5 \%$ of all the problems hindering the activities of WDCs in the study area. Another crucial factor stated both during quantitative and qualitative was the issue of motivation which accounted for about $10.8 \%$ of all respondents, all these issues were in line with earlier studies [19], [20], [21], [22].

\section{Conclusion And Recommendations}

WDCs provide basic health information to the people through sensitisation and mobilisation of people for health promotion and intervention programmes at the village, household community levels. They extend appropriate health care seeking behavior to the masses particularly in rural areas. The study was carried out in Ado-Odo/Ota Local Government Area to examine the potential influence of ward development committees (WDCs) in providing health support services. It was found out that WDCs activities range from engagement in promoting immunisation programmes, engagement in health education and promotion, environmental waste disposal and sanitation education to collaboration with government agencies and NGOs. The major challenges facing the smooth operation of their activities were raveled such as financial constraint need for vehicle and bad road, office apartment or secretariat, lack of equipment such as public address system(PAS), furniture, instructional materials, fans, etc and members' motivation. The policy recommendations were suggested on funding of WDCs in order to facilitate their activities. The financial incentive were also suggested as most of these volunteers are jobless and those in jobs forgoing their livelihood for the day to attend meetings or intervention programmes may entail more on their families. In addition, Government should provide vehicle, infrastructure especially water supply facility, road, instructional materials including posters for both indoors and out door publicity and enlightenment campaign.

\section{Acknowledgement}

The author acknowledges the assistance rendered by the Health Educator and his colleagues in this local government during the study period. In addition, I appreciate all the respondents in all the participating wards and colleagues for their valuable inputs and suggestions to this paper. 


\section{References}

[1] Federal Ministry of Health, Revised national health policy. Abuja: Federal Ministry of Health, 2004.

[2] I. S. Abdulraheem, A. R. Olapipo, and M. O. Amodu, (2012). Primary health care services in Nigeria: Critical issues and strategies for enhancing the use by the rural communities. Journal of Public Health and Epidemiology, 4(1), 2012, 5-13.

[3] Alma-Ata, Declaration of alma-ata international conference on primary health care, jointly sponsored by the WHO and UNICEF, USSR, 6-12 September 1978.

[4] G. E. D. Omuta, A. G. Onokerhoraye, F. Okonofua, G. Obanovwe, E. Isah, J. Chiwuzie, F. Okoro, F. Onojeta, F. Omoraka, J. Eregare, and E. Akpomera, (2014). Perspectives on Primary Health Care in Nigeria: Past, present and Future, Centre for Population and Environmental Development Monograph Series 10, 2014, 1-77.

[5] D. E. Azuh, A. E. Azuh, E. J. Iweala, D. Adeloye, M. Akanbi, and R. C. Mordi, Factors influencing maternal mortality among rural communities in southwestern Nigeria, Journal International of Women's Health 9, 2017, 179-188.

[6] M. D. Gupta, V. Gauri, and S. Khemani, Decentralized delivery of primary health services in Nigeria: survey evidence from the states of Lagos and Kogi, Washington: The World Bank, 2004.

[7] Nigeria Federal Ministry of Health, Technical report on national study on essential obstetric care facilities in Nigeria, Abuja Nigeria: Federal Ministry of Health, 2003.

[8] H. V. Doctor, S. E. Findley, A. Ager, G. Cometto, G. Y. Afenyadu, F. Adamu, C. Green, Using community-based research to shape the design and delivery of maternal health services in Northern Nigeria, Reproductive Health Matters, 20(39), 2012, 104112.

[9] S. S. Sule, K. T. Ijadunola, A. A. Onayade, A. O. Fatusi, R. O. Soetan, F. A. Connell, Utilization of primary health care facilities: lessons from a rural community in southwest, Nigeria. Niger. J. Med., 17(1), 2008, 98-106.

[10] U. Okoli, S. A. Mohammed, C. Ejeckam, Strengthening primary health care services in rural Nigeria: the potential of using midwives as skilled birth attendants, Health Syst Policy Res. 3(2), 2016, 1-7.

[11] H. Ekwuruke, Health care delivery system in rural areas, Panorama: Global online Publication.2005, http://www. tigweb.org/express/panorama.

[12] G. O. Shaibu, Primary healthcare and rural development in Dekina local government area of Kogi State, Economics, 1 (1), 2014, 45-54.

[13] Azuh Dominic Ezinwa, Child survival under threat. B. R. Delhi: Publishing Corporation, 1994.

[14] S. Metiboba, Social factors, community participation and health, development of the Okun Yoruba of Ijumu in Kogi State, Nigeria, doctoral diss., University of Ilorin, Nigeria, 2005.

[15] National Bureau Statistics, .Nigeria multiple indicator cluster survey 2011 main report,. Abuja: National Bureau Statistics, 2013.

[16] D. Florin, and J. Dixon, Public involvement in health care, BMJ 2004,328 (7432), 2004, 159-161.

[17] E. Mike, Community participation in phc services in Nigeria. Available at www.ngnhc.org/ 2010.

[18] Federal Ministry of Health, Integrated maternal, newborn and child health strategy, Abuja: Federal Ministry of Health, 2007.

[19] R. Beaglehole, D. Sanders, and M. Dal Poz, The public health workforce in sub-Saharan Africa: challenges and opportunities, Ethn Dis.; 13 (2 Suppl 2), 2003.

[20] World Bank, Decentralized delivery of primary health services in nigeria: survey evidence from the states of lagos and kogi, African Region Human Development Working Papers Series, 2003.

[21] World Bank, Improving Primary Health Care Delivery in Nigeria: Evidence from Four States, Washington: World Bank African Region, 2010.

[22] D. O. Adeyemo, Local government and health care delivery in Nigeria: a case study, Journal of Human Ecology, 18(2), 2005, 149160 . 